\title{
The Synthesis, Structure and Physical Properties of the Layered Ruthenocuprates $\mathrm{RuSr}_{2} \mathrm{GdCu}_{2} \mathrm{O}_{8}$ and $\mathrm{Pb}_{2} \mathrm{Sr}_{2} \mathrm{Cu}_{2} \mathrm{RuO}_{8} \mathrm{Cl}$
}

\author{
Abbie C. Mclaughlin and J. Paul Attfield \\ Department of Chemistry, University of Cambridge, Lensfield Road, Cambridge CB2 \\ 1EW and Interdisciplinary Research Centre in Superconductivity, Department of \\ Physics, University of Cambridge, Madingley Road, Cambridge CB3 0HE, UK.
}

\begin{abstract}
Studies of the structure and physical properties of the layered ruthenocuprates $\mathrm{RuSr}_{2} \mathrm{GdCu}_{2} \mathrm{O}_{8}$ and $\mathrm{Pb}_{2} \mathrm{Sr}_{2} \mathrm{Cu}_{2} \mathrm{RuO}_{8} \mathrm{Cl}$ are reviewed. $\mathrm{RuSr}_{2} \mathrm{GdCu}_{2} \mathrm{O}_{8}$ is a weak ferromagnetic superconductor and doping studies have shown that it is possible to tune the magnetic and superconducting transitions simultaneously. The average crystal structure of $\mathrm{RuSr}_{2} \mathrm{GdCu}_{2} \mathrm{O}_{8}$ is tetragonal at both 10 and $295 \mathrm{~K}$ (space group $\mathrm{P} 4 / \mathrm{mmm}$ ), but a $\sqrt{2} a \times \sqrt{2} a \times c$ superstructure resulting from coherent rotations of the $\mathrm{RuO}_{6}$ octahedra within subdomains of 50-200 $\AA$ is observed by selected area electron diffraction (SAED). The same tilts and rotations of the $\mathrm{RuO}_{6}$ octahedra are observed in semiconducting $\mathrm{Pb}_{2} \mathrm{Sr}_{2} \mathrm{Cu}_{2} \mathrm{RuO}_{8} \mathrm{Cl}$, which has strikingly similar magnetic properties to $\mathrm{RuSr}_{2} \mathrm{GdCu}_{2} \mathrm{O}_{8}$. Antiferromagnetic order is observed in the $10 \mathrm{~K}$ neutron diffraction pattern with a Ru moment of 1.1(1) $\mu_{\mathrm{B}}$, but a spin-flop transition is observed above a field of $0.5 \mathrm{~T}$.
\end{abstract}

\section{Introduction}

The (ferro)magnetic superconductor $\mathrm{RuSr}_{2} \mathrm{GdCu}_{2} \mathrm{O}_{8}$ [1-21] (Fig. 1) is an extremely interesting material, with a maximum $\mathrm{T}_{\mathrm{c}}=37 \mathrm{~K}$ and $\mathrm{T}_{\mathrm{M}}=136 \mathrm{~K}$, where $T_{c}$ is the superconducting temperature and $T_{M}$ is the Curie temperature. The superconductivity occurs in the $\mathrm{CuO}_{2}$ layers and the ferromagnetism arises in the $\mathrm{RuO}_{2}$ layers. $\mu \mathrm{SR}$ studies have demonstrated that the material is microscopically uniform with no evidence of spatial phase separation of the superconducting and magnetic regions [4]. Initial SQUID magnetometry results showed that the magnetic order in the ruthenate planes was predominantly ferromagnetic and this persists through the onset of superconductivity at $37 \mathrm{~K}$ to the lowest temperatures investigated $(1.9 \mathrm{~K})[1]$. Variable field measurements of $\mathrm{RuSr}_{2} \mathrm{GdCu}_{2} \mathrm{O}_{8}$ showed hysteresis with a remanent moment of $0.12 \mu_{\mathrm{B}}$ indicative of a ferromagnetic component in zero field. However G-type antiferromagnetic order within the $\mathrm{RuO}_{2}$ planes was subsequently observed from neutron scattering [10] experiments. In this model the Ru spins are aligned antiparallel to their neighbours in the $a b$ plane and along $c$ resulting in a doubling of the unit cell in all three directions. The direction of the spins in this model is parallel to the tetragonal $c$ axis. An upper limit of $0.1 \mu_{\mathrm{B}}$ was obtained for the ferromagnetic component, which appears to contradict results from SQUID magnetometry and electronic paramagnetic resonance experiments [18]. 
Variable field neutron diffraction studies of $\mathrm{RuSr}_{2} \mathrm{GdCu}_{2} \mathrm{O}_{8}$ showed that the $\mathrm{Ru}$ spins cant into a ferromagnetic arrangement upon the application of a magnetic field and at $7 \mathrm{~T}$ the $\mathrm{Ru}$ spins are fully ferromagnetically ordered. $\mathrm{Gd}^{3+}$ is paramagnetic down to $2.5 \mathrm{~K}$ and orders with the G-type antiferromagnetic structure below this temperature [10]. It is difficult to perform neutron diffraction experiments on $\mathrm{RuSr}_{2} \mathrm{GdCu}_{2} \mathrm{O}_{8}$ because Gd has an extremely high absorption cross section for thermal neutrons and isotopic enrichment with ${ }^{160} \mathrm{Gd}$ is necessary. Only two antiferromagnetic diffraction peaks have been observed in studies to date $[10,19]$ and it is therefore difficult to know whether the $\mathrm{Ru}$ spins are canted in the ground state.

$\mathrm{RuSr}_{2} \mathrm{YCu}_{2} \mathrm{O}_{8}$ has recently been synthesised under a pressure of $5.5 \mathrm{GPa}$ [22]. It is superconducting at $\mathrm{T}_{c} \geq 25 \mathrm{~K}$ and appears to be ferromagnetic, $\mathrm{T}_{\mathrm{M}}$ $=149 \mathrm{~K}$, from SQUID magnetometry experiments. Neutron diffraction on this material has also evidenced antiferromagnetic order with a G-type structure and an increased intensity on the [001] peak giving an estimate for the ferromagnetic moment of $0.3 \mu_{\mathrm{B}}$. Only the $\left[\frac{1}{2} \frac{1}{2} \frac{1}{2}\right]$ magnetic diffraction peak was observed from neutron diffraction on $\mathrm{RuSr}_{2} \mathrm{YCu}_{2} \mathrm{O}_{8}$ due to the low signal to noise ratio and so it is still impossible to know whether the spins are canted in the ground state. However the observation of a ferromagnetic component on the [001] peak at $\sim 145 \mathrm{~K}$ which is equivalent to $0.3 \mu_{\mathrm{B}}$ at $10 \mathrm{~K}$ gives increasing evidence of this. Upon application of a magnetic field the intensity of the antiferromagnetic $\left[\frac{1}{2} \frac{1}{2} \frac{1}{2}\right]$ peak decreases and the magnetic structure becomes increasingly ferromagnetic as for $\mathrm{RuSr}_{2} \mathrm{GdCu}_{2} \mathrm{O}_{8}$ [10]. Hence it appears that coexisting super-

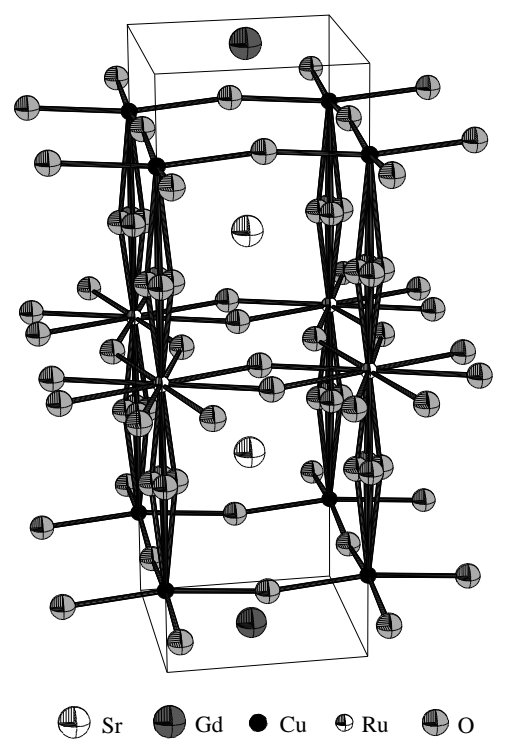

Fig. 1. The average crystal structure of $\mathrm{RuSr}_{2} \mathrm{GdCu}_{2} \mathrm{O}_{8}$ showing the disordered rotations and tilts of the $\mathrm{RuO}_{6}$ octahedra. 
conductivity and weak ferromagnetism occurs in these ruthenocuprates with a transition to full ferromagnetism at high fields. Coexisting ferromagnetism and superconductivity have also been observed in the 1222-type ruthenocuprates $\mathrm{RuSr}_{2} \mathrm{RE}_{2-x} \mathrm{Ce}_{x} \mathrm{Cu}_{2} \mathrm{O}_{10}[1,2] \mathrm{RE}=\mathrm{Eu}, \mathrm{Gd}$. So far no evidence of antiferromagnetism has been observed from neutron diffraction experiments on these materials [23] and SQUID magnetometry experiments on $\mathrm{RuSr}_{2} \mathrm{EuCeCu}_{2} \mathrm{O}_{10}$ have indicated a sizeable ferromagnetic component.

In this paper our studies of the structural and physical properties of $\mathrm{RuSr}_{2} \mathrm{Gd}$ $\mathrm{Cu}_{2} \mathrm{O}_{8}$ will be reviewed. A new phase $\mathrm{Pb}_{2} \mathrm{Sr}_{2} \mathrm{Cu}_{2} \mathrm{RuO}_{8} \mathrm{Cl}$ which has strikingly similar magnetic properties to $\mathrm{RuSr}_{2} \mathrm{GdCu}_{2} \mathrm{O}_{8}$ has recently been synthesised [24] and its basic structural and physical properties are discussed within.

\section{The Structure and Microstructure of $\mathrm{RuSr}_{2} \mathrm{GdCu}_{2} \mathrm{O}_{8}$}

The physical properties of $\mathrm{RuSr}_{2} \mathrm{GdCu}_{2} \mathrm{O}_{8}$ are strongly dependent on the preparation conditions [1]. An "as prepared" sample [5] synthesised by heating in flowing oxygen for 10 hours at $1050{ }^{\circ} \mathrm{C}$ and $1055^{\circ} \mathrm{C}$ has $\mathrm{T}_{\mathrm{c}} \geq 21 \mathrm{~K}$. However annealing the same sample for 7 days in flowing oxygen at $1050{ }^{\circ} \mathrm{C}$ increases $\mathrm{T}_{\mathrm{C}}$ to $37 \mathrm{~K}$ and halves the $300 \mathrm{~K}$ resistivity. We have shown that this occurs due to features of the structure and microstructure of $\mathrm{RuSr}_{2} \mathrm{GdCu}_{2} \mathrm{O}_{8} \cdot \mathrm{RuSr}_{2} \mathrm{GdCu}_{2} \mathrm{O}_{8}$ has a tetragonal unit cell at all temperatures [5,6] (space group $\mathrm{P} 4 / \mathrm{mmm}, a=$ 3.83955(1), $c=11.57239(7) \AA$ ) and is cation and oxygen stoichiometric (Fig. 1). Thermogravimetric analysis performed on the annealed sample gave an oxygen stoichiometry of $7.99 \pm 0.03$. Disorder of the oxygen atoms in the ruthenate planes and the apical atoms linking the $\mathrm{CuO}_{5}$ units and the $\mathrm{RuO}_{6}$ octahedra have been observed from synchrotron X-ray diffraction measurements. The inplane Ru-O bond length $(1.969(2) \AA)$ is larger than the in-plane $\mathrm{Cu}-\mathrm{O}$ bond length (1.9268(4) $\AA$ ) at $295 \mathrm{~K}$ and it is this bond mismatch which results in rotations of the $\mathrm{RuO}_{6}$ octahedra around the $c$ axis, by $13^{\circ}$ at $295 \mathrm{~K}$, with a net stabilisation of the structure. There is also a slight tilting of the octahedra, which reduces the $\mathrm{Cu}-\mathrm{O}-\mathrm{Ru}$ angle to $\sim 173^{\circ}$. The thermal contraction of the inplane $\mathrm{Cu}-\mathrm{O}$ bond is greater than that of the $\mathrm{Ru}-\mathrm{O}$ bond distances and therefore results in an increase of the bond mismatch between the two bond lengths. This has the effect of rotating the $\mathrm{RuO}_{6}$ octahedra around $c$ with a slightly increasing angle as the temperature decreases. Hence the displacement of the oxygen atoms actually increases with decreasing temperature proving that they are due to static disorder within the average structure.

The rotations of the $\mathrm{RuO}_{6}$ octahedra around $c$ that are observed from synchrotron X-ray diffraction on $\mathrm{RuSr}_{2} \mathrm{GdCu}_{2} \mathrm{O}_{8}$ would give rise to a $\sqrt{2} a \times \sqrt{2} a$ $\mathrm{x} c$ superstructure if long-range ordered. This superstructure was observed in SAED patterns for the "as prepared" $\mathrm{RuSr}_{2} \mathrm{GdCu}_{2} \mathrm{O}_{8}$ sample viewed down the [001] axis (Fig. 2) [5]. All of the main diffraction spots in the SAED pattern could be indexed by the basic tetragonal unit cell and the additional weak spots indicated the formation of a $\sqrt{2} a \times \sqrt{2} a \times c$ supercell. However there was no evidence for this supercell from synchrotron X-ray diffraction measurements 


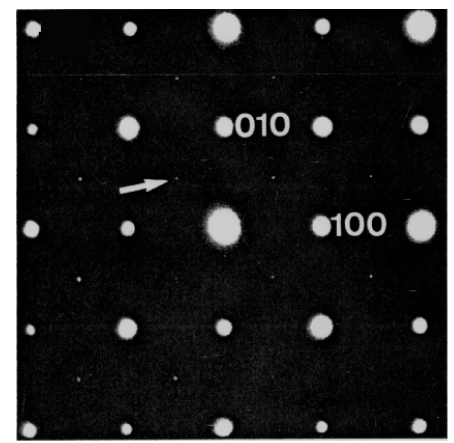

Fig. 2. The SAED pattern from the as prepared $\mathrm{RuSr}_{2} \mathrm{GdCu}_{2} \mathrm{O}_{8}$ sample viewed down the [001] direction. The additional weak spots arrowed evidence the $\sqrt{2} a \times \sqrt{2} a \times c$ superstructure.

$[5,6]$ which have an extremely high sensitivity to weak diffraction peaks. A High Resolution Transmission Electron Microscopy (HRTEM) image for the annealed $\mathrm{RuSr}_{2} \mathrm{GdCu}_{2} \mathrm{O}_{8}$ sample shows dark rectangular boundaries which divide the structure into sub-domains of 50-200 $\AA$ (Fig. 3). It was concluded that there is no long range order of the $\mathrm{RuO}_{6}$ octahedra and the ordering of the $\mathrm{RuO}_{6}$ octahedra over many unit cells is shown in Fig. 4. Anti-phase boundaries of width $a$ occur every 50-200 $\AA$ as seen in the HRTEM image. At an anti-phase boundary the sense of rotation of the $\mathrm{RuO}_{6}$ octahedra is reversed, but the remainder of the structure is unaffected. This therefore explains why the electron diffraction but not the X-ray diffraction sees the superstructure, because $50-200 \AA$ is too short to give rise to superstructure peaks in the X-ray data.

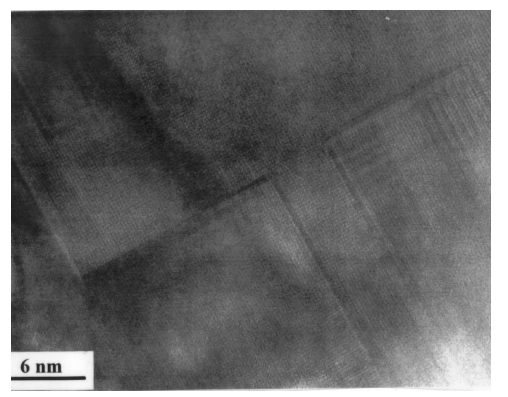

Fig. 3. HRTEM image of the annealed $\mathrm{RuSr}_{2} \mathrm{GdCu}_{2} \mathrm{O}_{8}$ sample viewed down the [001] zone axis showing rectangular anti-phase boundaries.

The $c / a$ axis ratio for $\mathrm{RuSr}_{2} \mathrm{GdCu}_{2} \mathrm{O}_{8}$ at $3.015(295 \mathrm{~K})$ is very close to ideal for a triple perovskite, for comparison $c / a$ varies between 3.032 and 3.066 as $\delta$ 
varies from 0 to 1 in $\mathrm{YBa}_{2} \mathrm{Cu}_{3} \mathrm{O}_{7-\delta}$ [25]. The near coincidence of $a$ and $b$ with $c / 3$ in $\mathrm{RuSr}_{2} \mathrm{GdCu}_{2} \mathrm{O}_{8}$ results in the formation of many small domains with $c$ in one of the three equivalent directions as shown in the HRTEM image for the "as prepared" $\mathrm{RuSr}_{2} \mathrm{GdCu}_{2} \mathrm{O}_{8}$ sample (Fig. 5). The areas labelled A, B, and $\mathrm{C}$ are individual domains. The $90^{\circ}$ angle between the $\mathrm{CuO}_{2}$ planes meeting at the boundaries strongly reduces the supercurrent transport leading to high granularity, a low transport $\mathrm{T}_{\mathrm{c}}$ and a high residual resistivity in the "as prepared" sample. The microstructure of $\mathrm{RuSr}_{2} \mathrm{GdCu}_{2} \mathrm{O}_{8}$ therefore depends on the synthesis and annealing time; when annealing the sample in oxygen at high temperature for a long time, the improvement in the superconducting properties is due to an increase in domain size, rather than a change in cation composition or oxygen content. This was later confirmed by heat capacity studies which showed that the thermodynamic critical temperature occurs at $46 \mathrm{~K}$ in both samples [9].

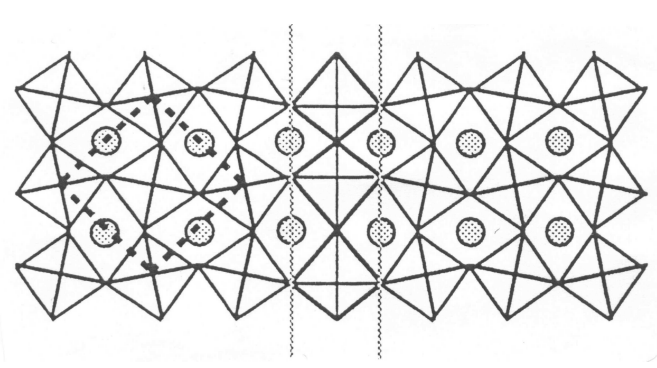

Fig. 4. A model for the rotations of the $\mathrm{RuO}_{6}$ octahedra around $\mathrm{c}$ in the $\mathrm{RuSr}_{2} \mathrm{GdCu}_{2} \mathrm{O}_{8}$ structure, resulting in the $\sqrt{2} a \times \sqrt{2} a \times c$ superstructure shown in the $x y$ plane by broken lines. An anti-phase boundary is also shown.

No large changes in any of the bond lengths or angles have been observed by powder X-ray diffraction when the Ru moments order at $132 \mathrm{~K}$ [6]. The atomic displacement U-factor for the in-plane $\mathrm{O}(2)$ changes from 0.009 to $0.011 \AA^{2}$ and is the only observed structural anomaly accompanying the magnetic ordering transition. However a variable temperature powder neutron diffraction study of a ${ }^{160} \mathrm{Gd}$-substituted $\mathrm{RuSr}_{2} \mathrm{GdCu}_{2} \mathrm{O}_{8}$ sample observed abrupt changes in the $\mathrm{Cu}$ $\mathrm{O}(2)-\mathrm{Cu}$ buckling angle and the $\mathrm{Cu}-\mathrm{Cu}$ interlayer distance at $\mathrm{T}_{\mathrm{M}}[11]$ and hence the anomaly in the U-factor of $\mathrm{O}(2)$ suggests that similar structural changes occur over a shorter range.

The observation of this anomaly at $\mathrm{T}_{\mathrm{M}}$ in the $\mathrm{CuO}_{2}$ planes rather than in the $\mathrm{RuO}_{6}$ octahedra is surprising but correlates with magnetoresistance measurements performed on $\mathrm{RuSr}_{2} \mathrm{GdCu}_{2} \mathrm{O}_{8}$ [26] which show a strong exchange interaction $(\mathrm{J}=35 \mathrm{meV})$ between the spins and the carriers comparable to the superconducting energy gap. It was concluded that the carriers are associated with both $\mathrm{CuO}_{2}$ and $\mathrm{RuO}_{2}$ bands i.e. itinerant electron ferromagnetism because suppression of superconductivity due to exchange is expected if the carriers are 
only on the $\mathrm{CuO}_{2}$ planes. Therefore if the $\mathrm{Ru}$ moments are itinerant then this could cause anomalies due to magnetic ordering to manifest in the $\mathrm{CuO}_{2}$ planes rather than in the $\mathrm{RuO}_{6}$ octahedra as observed in the synchrotron X-ray [5] and neutron diffraction [11] data. However this contradicts the recent observation of antiferromagnetic order in the ruthenate planes from a different neutron diffraction study [10].

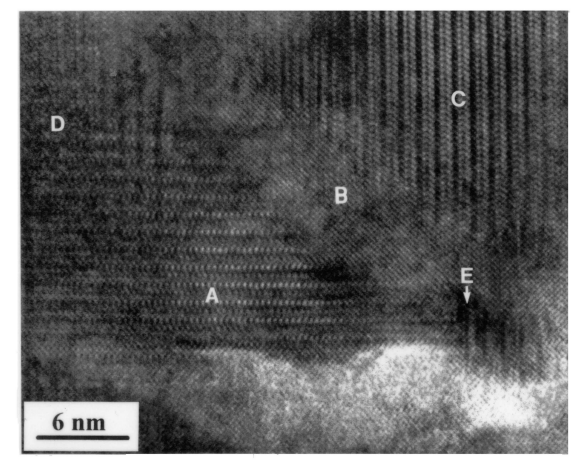

Fig. 5. HRTEM image of a regions of the "as prepared" $\mathrm{RuSr}_{2} \mathrm{GdCu}_{2} \mathrm{O}_{8}$ sample showing the multi-domain nature of the microstructure. The areas labelled $\mathrm{A}, \mathrm{B}$, and $\mathrm{C}$ are individual domains. A and $\mathrm{C}$ are both orientated in the [100] direction, but rotated by $90^{\circ}$ from one another whilst domain $\mathrm{B}$ ([001] orientation) is perfectly intergrown between $\mathrm{A}$ and $\mathrm{C}$ without any amorphous boundaries. Area D shows an intergrowth of $\mathrm{A}$ and $\mathrm{B}$ with an interface on the [100] plane for both domains. The intergrowth of $\mathrm{A}$ and $\mathrm{B}$ in the area $\mathrm{E}$ is between the [010] plane of $\mathrm{A}$ and the [001] plane of B.

$\mathrm{RuSr}_{2} \mathrm{GdCu}_{2} \mathrm{O}_{8}$ is thought to be a canted antiferromagnet (a weak ferromagnet). The slight canting of the Ru moments can arise due to a DzyaloshinskyMoriya $[27,28]$ interaction (antisymmetric exchange interaction between neighbouring $\mathrm{Ru}$ moments) which is non-zero due to the tilts and rotations of the $\mathrm{RuO}_{6}$ octahedra. Previous transport measurements on $\mathrm{RuSr}_{2} \mathrm{GdCu}_{2} \mathrm{O}_{8}$ indicated a hole concentration on the $\mathrm{CuO}_{2}$ planes of $p=0.07$ [1]. Bond valence summations [29] on $\mathrm{RuSr}_{2} \mathrm{GdCu}_{2} \mathrm{O}_{8}$ resulted in a large estimation of the hole concentration in the cuprate planes; $p=0.44$. The canting of the $\mathrm{Ru}$ moments due to the Dzyaloshinsky-Moriya interaction could lead to magnetic trapping or scattering of the holes and hence transport properties typical of underdoped cuprates, whilst the apparent hole concentration measured crystallographically is much higher. However Brown et al [30] have shown that bond valence sum calculations do not give accurate results if the bond lengths are strained. The $\mathrm{Cu}-\mathrm{O}$ bonds are strained in $\mathrm{RuSr}_{2} \mathrm{GdCu}_{2} \mathrm{O}_{8}$ due to the bond mismatch between the ruthenate and cuprate layers which could therefore explain the discrepancy in the two estimations of $p$ from transport measurements and bond valence sums. 


\section{Doping Studies of $\mathrm{RuSr}_{2} \mathrm{GdCu}_{2} \mathrm{O}_{8}$}

The substitution of $\mathrm{Ru}$ by the non-magnetic, fixed valent cations $\mathrm{Nb}^{5+}$ and $\mathrm{Sn}^{4+}$ has helped in the understanding of the charge distribution and magnetism of $\mathrm{RuSr}_{2} \mathrm{GdCu}_{2} \mathrm{O}_{8}$. The hole doping of the copper oxide planes necessary to induce superconductivity arises from the overlap of the minority spin $\mathrm{Ru}: \mathrm{t}_{2 g}$ and the $\mathrm{Cu}: 3 \mathrm{~d}_{x^{2}-y^{2}}$ bands and the formula is written as $\mathrm{Ru}^{5-2 p_{0}} \operatorname{Sr}_{2} \mathrm{Gd}\left(\mathrm{Cu}^{2+p_{0}}\right)_{2} \mathrm{O}_{8}$ to show the average $\mathrm{Ru}$ and $\mathrm{Cu}$ oxidation states [31,32].

The $\mathrm{Ru}_{1-x} \mathrm{M}_{x} \mathrm{Sr}_{2} \mathrm{GdCu}_{2} \mathrm{O}_{8}$ solid solutions have been studied by powder $\mathrm{X}$ ray diffraction $[31,32]$ and the observation of overall increases in the lattice parameters, cell volume, Sr-O and $\mathrm{Ru} / \mathrm{M}-\mathrm{O}$ bond lengths are in accordance with the substitution of the slightly larger $\mathrm{Sn}^{4+}$ and $\mathrm{Nb}^{5+}$ for $\mathrm{Ru}^{4+}{ }^{5+}$. The $\mathrm{RuO}_{6}$ octahedra were found to rotate around $c$ with a greater angle as $x$ increases in the $\mathrm{Ru}_{1-x} \mathrm{M}_{x} \mathrm{Sr}_{2} \mathrm{GdCu}_{2} \mathrm{O}_{8}$ solid solutions due to the increased bond mismatch between the in plane $\mathrm{Ru}-\mathrm{O}$ and $\mathrm{Cu}-\mathrm{O}$ bonds. An increase in the average apical $\mathrm{Cu}-\mathrm{O}$ bond was also observed with $\mathrm{Nb}$ substitution due to the change in charge transfer from the minority spin $\mathrm{Ru}: \mathrm{t}_{2 g}$ to the $\mathrm{Cu}: 3 \mathrm{~d}_{x^{2}-y^{2}}$ bands $[31,32]$. Similar results were found upon reduction of $\mathrm{YBa}_{2} \mathrm{Cu}_{3} \mathrm{O}_{7}[25]$ in which the apical bond increases from 2.328(3) $\AA$ to 2.380(4) $\AA$ and the $\mathrm{T}_{\mathrm{c}}$ decreases from 69 to $56 \mathrm{~K}$.

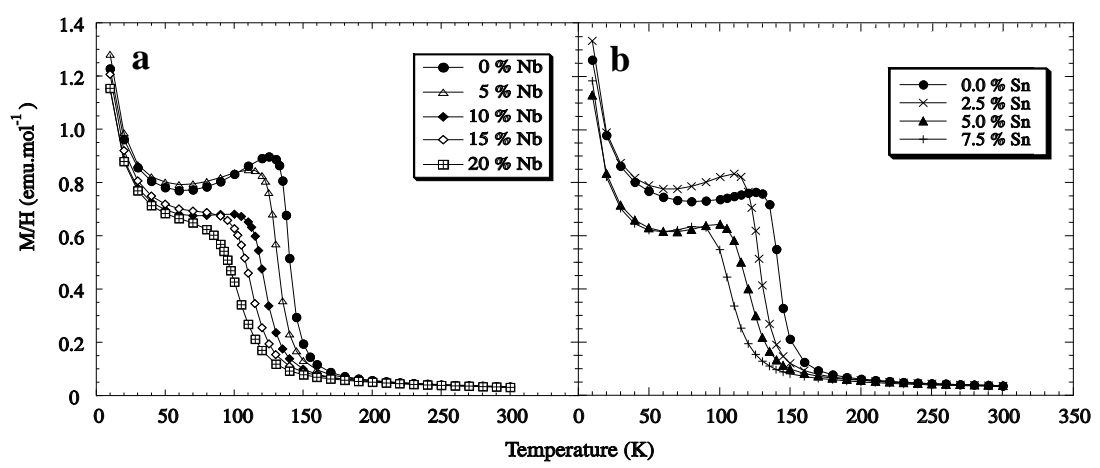

Fig. 6. Variation of molar susceptibility with $x$ in (a) the $\mathrm{Ru}_{1-x} \mathrm{Nb} x \mathrm{Sr}_{2} \mathrm{GdCu}_{2} \mathrm{O}_{8}$ solid solutions and (b) $\mathrm{Ru}_{1-x} \mathrm{Sn} x \mathrm{Sr}_{2} \mathrm{GdCu}_{2} \mathrm{O}_{8}$ solid solutions.

The magnetic properties of $\mathrm{RuSr}_{2} \mathrm{GdCu}_{2} \mathrm{O}_{8}$ were found to change dramatically with $\mathrm{Sn} / \mathrm{Nb}$ substitution for Ru. Magnetic hysteresis loops recorded at $10 \mathrm{~K}$ confirmed the ferromagnetic order in all samples. A reduction of the Curie temperature $\left(\mathrm{T}_{\mathrm{M}}\right)$ and a broadening of the magnetic transition were clearly observed with both $\mathrm{Sn}$ and $\mathrm{Nb}$ substitution (Fig. 6). The Ru moment, remanent moment and coercive field measured for all samples were also found to decrease smoothly with $x$ in the $\mathrm{Ru}_{1-x} \mathrm{M}_{x} \mathrm{Sr}_{2} \mathrm{GdCu}_{2} \mathrm{O}_{8}$ solid solutions. The fixed valent diamagnetic cations do not contribute electronic states close to the Fermi level and therefore the substitution of diamagnetic $\mathrm{Sn}^{4+}$ and $\mathrm{Nb}^{5+}$ dilutes the ferromagnetism in the $\mathrm{RuO}_{2}$ layers leading to a rapid decrease in the Curie temperature 
from $136 \mathrm{~K}$ to $103 \mathrm{~K}$ in $\mathrm{Ru}_{0.8} \mathrm{Nb}_{0.2} \mathrm{Sr}_{2} \mathrm{GdCu}_{2} \mathrm{O}_{8}$. The estimated moment per $\mathrm{Ru}$ atom decreases with $x$ due to the disorder of the spins incurred by substitution of the non-magnetic cations.
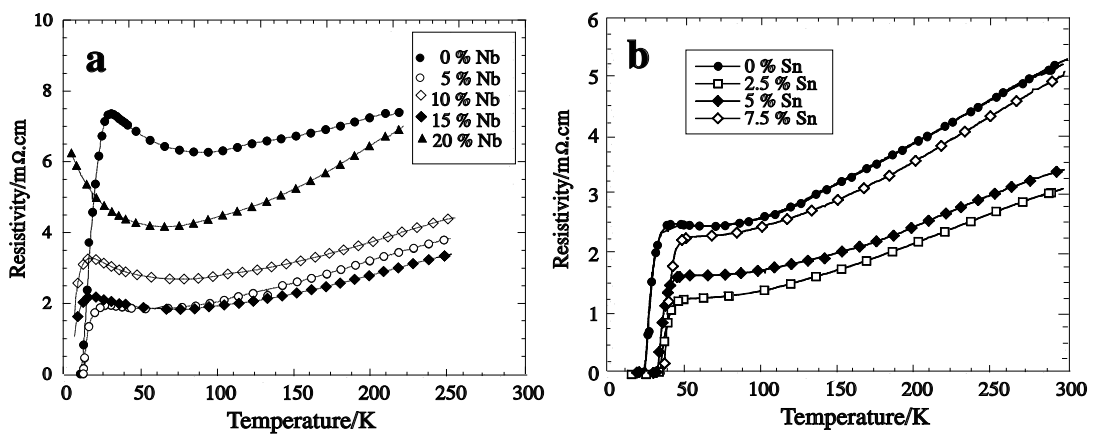

Fig. 7. Variation of the resistivity with $x$ for (a) the $\mathrm{Ru}_{1-x} \mathrm{Nb}_{x} \mathrm{Sr}_{2} \mathrm{GdCu}_{2} \mathrm{O}_{8}$ solid solutions and (b) the $\mathrm{Ru}_{1-x} \mathrm{Sn}_{x} \mathrm{Sr}_{2} \mathrm{GdCu}_{2} \mathrm{O}_{8}$ solid solutions.

Superconducting transitions were observed for the $\mathrm{Ru}_{1-x} \mathrm{Nb}_{x} \mathrm{Sr}_{2} \mathrm{GdCu}_{2} \mathrm{O}_{8}$ solid solutions with $x=0-0.15$ (Fig. $7(\mathbf{a})$ ) but not for $x=0.2$ down to 7 K. All the $\mathrm{Ru}_{1-x} \mathrm{Sn}_{x} \mathrm{Sr}_{2} \mathrm{GdCu}_{2} \mathrm{O}_{8}$ samples were superconducting (Fig. 7(b)) and the onset $\mathrm{T}_{\mathrm{c}}$ was found to increase from $38 \mathrm{~K}$ for $\mathrm{RuSr}_{2} \mathrm{GdCu}_{2} \mathrm{O}_{8}$ to 50 $\mathrm{K}$ in the $7.5 \%$ Sn sample. All samples were observed to be metallic $(\mathrm{d} \rho / \mathrm{dT}$ $>0$ ) although a semiconducting upturn was observed close to $\mathrm{T}_{\mathrm{c}}$. Therefore substitution of $\mathrm{Ru}^{4.84+}$ by $\mathrm{Nb}^{5+}$ leads to the removal of holes from the $\mathrm{CuO}_{2}$ planes so that the materials become more underdoped. This is supported by the increase in the $290 \mathrm{~K}$ Seebeck coefficient with $x$ in the $\mathrm{Ru}_{1-x} \mathrm{Nb}_{x} \mathrm{Sr}_{2} \mathrm{GdCu}_{2} \mathrm{O}_{8}$ solid solutions [31,32] and the decrease in $\mathrm{T}_{\mathrm{c}}$ to $19 \mathrm{~K}$ in the $15 \% \mathrm{Nb}$ sample. The opposite effect occurs upon Sn substitution; the hole concentration increases with a subsequent increase in $\mathrm{T}_{\mathrm{c}}$ to $50 \mathrm{~K}$ and a decrease in the Seebeck coefficient (Fig. 8). Thermogravimetric analysis on the $\mathrm{Ru}_{1-x} \mathrm{M}_{x} \mathrm{Sr}_{2} \mathrm{GdCu}_{2} \mathrm{O}_{8}$ solid solutions showed that there is no change in oxygen content with increasing $\mathrm{Nb}^{5+} / \mathrm{Sn}^{4+}$ substitution. The charge distribution in the doped ruthenocuprates was therefore written as $\left(\mathrm{Ru}^{5-2 p_{0}}\right)_{1-x} \mathrm{M}^{q}{ }_{x} \mathrm{Sr}_{2} \mathrm{Gd}\left(\mathrm{Cu}^{2+p_{0}+\Delta p}\right)_{2} \mathrm{O}_{8}$ where the extrinsic doping introduced by the substituents $\mathrm{M}$ of charge $q$ is $\Delta p=\left(5-q-2 p_{0}\right) x / 2$, assuming the initial doping level $p_{0}$ remains constant. The fitted value of $p_{0}$ is 0.08 .

The maximum $\mathrm{T}_{\mathrm{c}}$ for $\mathrm{RuSr}_{2} \mathrm{GdCu}_{2} \mathrm{O}_{8}$ has been estimated at $65(10) \mathrm{K}$ by fitting the values of the $\mathrm{T}_{\mathrm{c}}$ onset measured for the $\mathrm{Ru}_{1-x} \mathrm{M}_{x} \mathrm{Sr}_{2} \mathrm{GdCu}_{2} \mathrm{O}_{8}$ solid solutions to the quadratic equation $\mathrm{T}_{\mathrm{c}}=\mathrm{T}_{\mathrm{c}}^{\max }\left[1-82.6(p-0.16)^{2}\right]$ [33] (Fig. 9). This is in agreement with the $\mathrm{T}_{\mathrm{c}}^{\max }=72 \mathrm{~K}$ recently recorded for $\mathrm{Ru}_{1-x} \mathrm{Sr}_{2} \mathrm{Gd}$ $\mathrm{Cu}_{2+x} \mathrm{O}_{8-y}$ at optimal doping [34]. This is much lower than the highest $\mathrm{T}_{\mathrm{c}}$ of $105 \mathrm{~K}$ obtained for the 1212 cuprate $\left(\mathrm{Tl}_{0.5} \mathrm{~Pb}_{0.5}\right) \mathrm{Sr}_{2}(\mathrm{Ca}, \mathrm{Y}) \mathrm{Cu}_{2} \mathrm{O}_{7}$ [35]. It was speculated that this suppression could reflect a pairbreaking interaction with the ferromagnetic moments in the $\mathrm{RuO}_{2}$ plane. However this effect would be ex- 

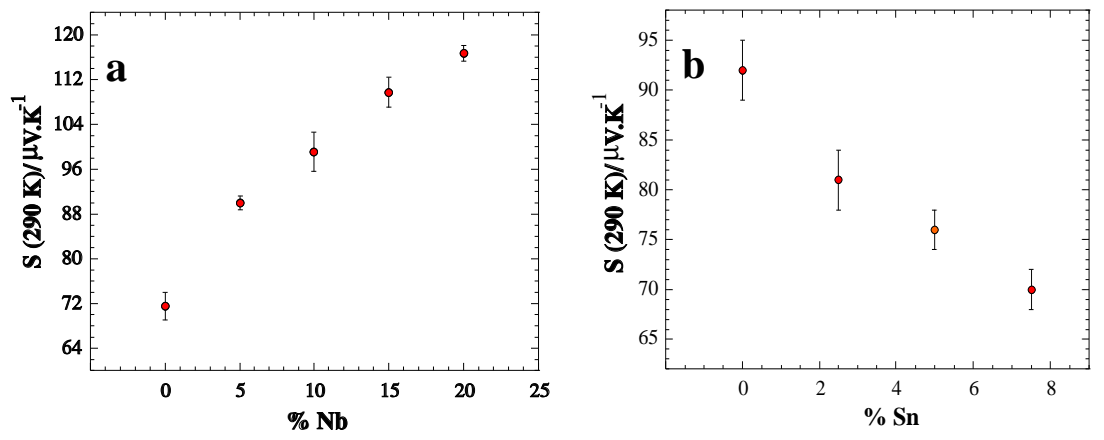

Fig. 8. Variation of the room temperature Seebeck coefficient with $x$ for (a) the $\mathrm{Ru}_{1-x} \mathrm{Nb}_{x} \mathrm{Sr}_{2} \mathrm{GdCu}_{2} \mathrm{O}_{8}$ solid solutions and (b) the $\mathrm{Ru}_{1-x} \mathrm{Sn}_{x} \mathrm{Sr}_{2} \mathrm{GdCu}_{2} \mathrm{O}_{8}$ solid solutions.

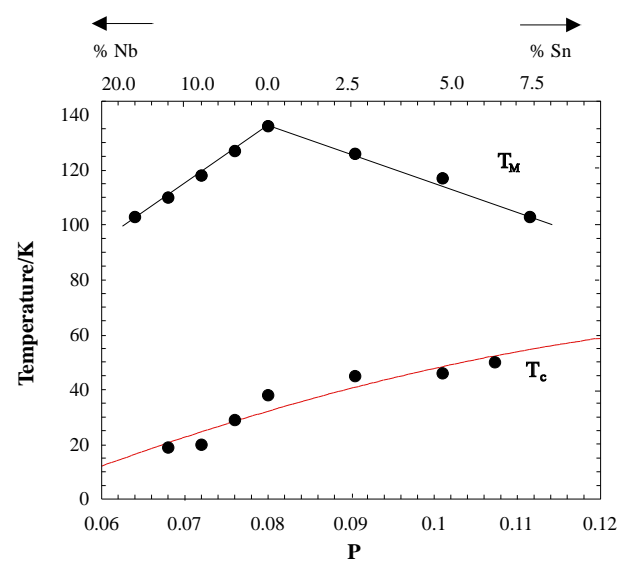

Fig. 9. The variation of the superconducting critical temperature $\left(\mathrm{T}_{\mathrm{c}}\right)$ and the Curie temperature $\left(\mathrm{T}_{\mathrm{M}}\right)$ with doping level $p$ (lower scale) and \% $\mathrm{Nb}$ or $\mathrm{Sn}$ (upper scale) in the $\mathrm{Ru}_{1-x} \mathrm{M}_{x} \mathrm{Sr}_{2} \mathrm{GdCu}_{2} \mathrm{O}_{8}$ solid solutions. The $\mathrm{T}_{\mathrm{c}}$ values are fitted by the quadratic expression supplied in the text.

pected to be greater in the undoped compound and it was concluded that the low estimate of $\mathrm{T}_{\mathrm{c}}^{\max }$ is due to the lattice strain from the bond mismatch between the cuprate and ruthenate layers which increases upon substitution of both $\mathrm{Sn}$ and Nb. The unusually short apical $\mathrm{Cu}-\mathrm{O}$ bond of $2.16 \AA$ in $\mathrm{RuSr}_{2} \mathrm{GdCu}_{2} \mathrm{O}_{8}$ provides evidence that the geometry of this tetragonal 1212 structure is not optimal for superconductivity. As a consequence bond valence sums give $p \sim 0.4$ for $\mathrm{RuSr}_{2} \mathrm{GdCu}_{2} \mathrm{O}_{8}$ whereas results from transport measurements led to an estimate of $p \sim 0.1$. It was originally thought that this discrepancy was due to a large number of holes trapped by defects or by the ferromagnetic order in the sample. However upon dilution of the weak ferromagnetism there was no evidence of a disproportionately large increase in $p$ from the room temperature Seebeck coef- 
ficient or the transport properties of the $\mathrm{Ru}_{1-x} \mathrm{M}_{x} \mathrm{Sr}_{2} \mathrm{GdCu}_{2} \mathrm{O}_{8}$ samples. Earlier results on $\mathrm{YBa}_{2} \mathrm{Cu}_{3} \mathrm{O}_{7-\delta}[30]$ have shown that bond valence sum calculations do not work well on structures under strain. The structure of $\mathrm{RuSr}_{2} \mathrm{GdCu}_{2} \mathrm{O}_{8}$ is strained due to the bond mismatch between the ruthenate and cuprate layers and it is therefore concluded that the actual hole concentration in the cuprate planes is $p \sim 0.08$ and that there are no additional, magnetically trapped holes.

\section{The Structure and Magnetic Properties of $\mathrm{Pb}_{2} \mathrm{Sr}_{2} \mathrm{Cu}_{2} \mathrm{RuO}_{8} \mathrm{Cl}$}

A new material $\mathrm{Pb}_{2} \mathrm{Sr}_{2} \mathrm{Cu}_{2} \mathrm{RuO}_{8} \mathrm{Cl}$ (Fig. 10) has recently been synthesised [24] enabling further study of the electronic and magnetic properties of the ruthenocuprates. This material is of similar structure to $\mathrm{RuSr}_{2} \mathrm{GdCu}_{2} \mathrm{O}_{8}$ but caesium chloride type $\mathrm{Pb}_{2} \mathrm{Cl}$ layers replace $\mathrm{Gd}$ making the material more convenient to study by neutron diffraction. Such a CsCl-type $\mathrm{Pb}_{2} \mathrm{Cl}$ layer also exists in the mineral ferrate $\mathrm{Pb}_{4} \mathrm{Fe}_{3} \mathrm{O}_{8} \mathrm{Cl}$ known as hematophanite [36,37] and the isostructural insulating materials $\mathrm{Pb}_{2} \mathrm{Sr}_{2} \mathrm{Cu}_{2} \mathrm{MO}_{8} \mathrm{Cl}(\mathrm{M}=\mathrm{Ta}, \mathrm{Nb}, \mathrm{Sb})[38-40]$.

$\mathrm{Pb}_{2} \mathrm{Sr}_{2} \mathrm{Cu}_{2} \mathrm{RuO}_{8} \mathrm{Cl}$ has been studied by TOF neutron diffraction between 295 and $10 \mathrm{~K}$ [24]. This phase is difficult to prepare free of secondary phases and the sample contained $73 \% \mathrm{~Pb}_{2} \mathrm{Sr}_{2} \mathrm{Cu}_{2} \mathrm{RuO}_{8} \mathrm{Cl}$ by mass with $8 \% \mathrm{CuO}$ and 19 \% "SrRuO ${ }_{3}$ ". An excellent Rietveld fit was obtained at all temperatures with a tetragonal $P 4 / \mathrm{mmm}$ symmetry structural model for the principal phase (a $=3.86681(9) \AA, c=15.3688(7) \AA$ at $295 \mathrm{~K})$. The oxygen atoms within the

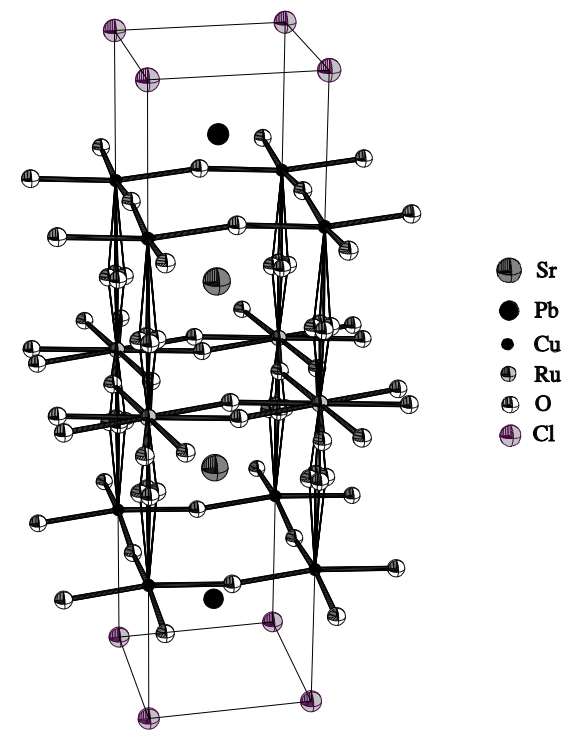

Fig. 10. The average crystal structure of $\mathrm{Pb}_{2} \mathrm{Sr}_{2} \mathrm{Cu}_{2} \mathrm{RuO}_{8} \mathrm{Cl}$ showing the tilts and rotations of the $\mathrm{RuO}_{6}$ octahedra. 
$\mathrm{RuO}_{6}$ planes and the oxygen atoms linking the $\mathrm{CuO}_{5}$ units and $\mathrm{RuO}_{6}$ octahedra (Fig. 10) were found to be disordered as observed for $\mathrm{RuSr}_{2} \mathrm{GdCu}_{2} \mathrm{O}_{8}$ [5,6]; the $\mathrm{RuO}_{6}$ octahedra are rotated by $13.4^{\circ}$ around the $z$ axis and are tilted away from this axis by $7.1^{\circ}$ at room temperature. A recent BVS calculation on $\mathrm{Pb}_{2} \mathrm{Sr}_{2} \mathrm{Cu}_{2} \mathrm{RuO}_{8} \mathrm{Cl}$ has shown that the hole transfer to the $\mathrm{CuO}_{2}$ planes is $\sim 0.1$ less than in $\mathrm{RuSr}_{2} \mathrm{GdCu}_{2} \mathrm{O}_{8}$; the apical $\mathrm{Cu}-\mathrm{O}$ distance $(2.24 \AA)$ is longer than that in $\mathrm{RuSr}_{2} \mathrm{GdCu}_{2} \mathrm{O}_{8}(2.16 \AA)$ at room temperature. Hence since $p$ was estimated at 0.08 in $\mathrm{RuSr}_{2} \mathrm{GdCu}_{2} \mathrm{O}_{8}$ it was concluded that the $\mathrm{CuO}_{2}$ planes in $\mathrm{Pb}_{2} \mathrm{Sr}_{2} \mathrm{Cu}_{2} \mathrm{RuO}_{8} \mathrm{Cl}$ are essentially undoped. $\mathrm{Pb}_{2} \mathrm{Sr}_{2} \mathrm{Cu}_{2} \mathrm{RuO}_{8} \mathrm{Cl}$ is semiconducting with a room temperature resistivity of $160 \Omega . \mathrm{cm}$ and there is no evidence for a superconducting transition at low temperatures, consistent with the copper oxide planes being too underdoped to superconduct.

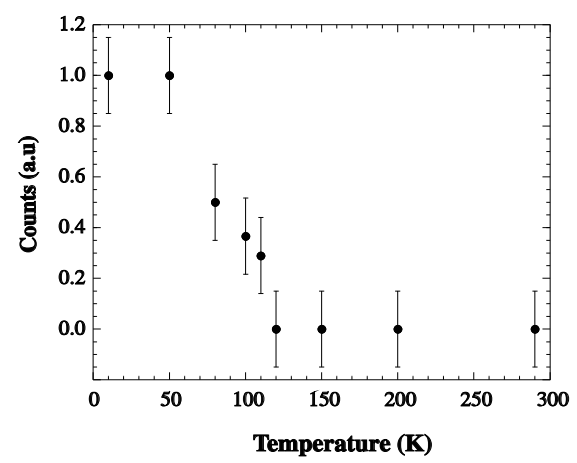

Fig. 11. Temperature dependence of the intensity of the magnetic $\left[\frac{1}{2} \frac{1}{2} \frac{1}{2}\right]$ neutron diffraction peak.

A variable temperature neutron study has shown that $\mathrm{Pb}_{2} \mathrm{Sr}_{2} \mathrm{Cu}_{2} \mathrm{RuO} \mathrm{O}_{8} \mathrm{Cl}$ appears to be antiferromagnetic below $120 \mathrm{~K}$ as the $\left[\frac{1}{2} \frac{1}{2} \frac{1}{2}\right]$ magnetic diffraction peak is observed below this temperature (Figs. 11 and 12). The low temperature neutron diffraction patterns were fitted with the same G-type antiferromagnetic model as for $\mathrm{RuSr}_{2} \mathrm{GdCu}_{2} \mathrm{O}_{8}$ [10]. The spins were assumed to lie parallel to the $c$ axis giving a refined $\mathrm{Ru}$ moment of $1.1(1) \mu_{\mathrm{B}}$. This value is within error of the value $\mu_{\mathrm{Ru}}=1.18(6) \mu_{\mathrm{B}}$ in $\mathrm{RuSr}_{2} \mathrm{GdCu}_{2} \mathrm{O}_{8}$ [10]. There was no observation of a change in the nuclear Bragg intensity of any of the $[00 l]$ peaks where the ferromagnetic contribution would be expected between $295 \mathrm{~K}$ and 10 K. A variable field neutron diffraction study has recently been performed on $\mathrm{Pb}_{2} \mathrm{Sr}_{2} \mathrm{Cu}_{2} \mathrm{RuO}_{8} \mathrm{Cl}$ [41]. These measurements have shown that at fields higher than $0.5 \mathrm{~T}$ the intensity of the $\left[\frac{1}{2} \frac{1}{2} \frac{1}{2}\right]$ magnetic peak decreases whilst an increase of the [003] peak intensity is observed corresponding to induced ferromagnetism in the $x y$ plane (Fig.13). No significant $\left[\frac{1}{2} \frac{1}{2} \frac{1}{2}\right]$ intensity was observed above 1.1 $\mathrm{T}$ and the effect of the magnetic field was found to be reversible; returning to zero field, the $\left[\frac{1}{2} \frac{1}{2} \frac{1}{2}\right]$ peak recovers its original intensity. Evidence of such a spinflop transition has previously been reported in $\mathrm{RuSr}_{2} \mathrm{GdCu}_{2} \mathrm{O}_{8}$ at $0.4 \mathrm{~T}$ [8] and 
$\mathrm{RuSr}_{2} \mathrm{YCu}_{2} \mathrm{O}_{8}[22]$. It was concluded that the field dependent magnetic order is common to the ruthenocuprate structures but further neutron diffraction experiments on a phase pure $\mathrm{Pb}_{2} \mathrm{Sr}_{2} \mathrm{Cu}_{2} \mathrm{RuO}_{8} \mathrm{Cl}$ sample will be necessary in order to confirm this.

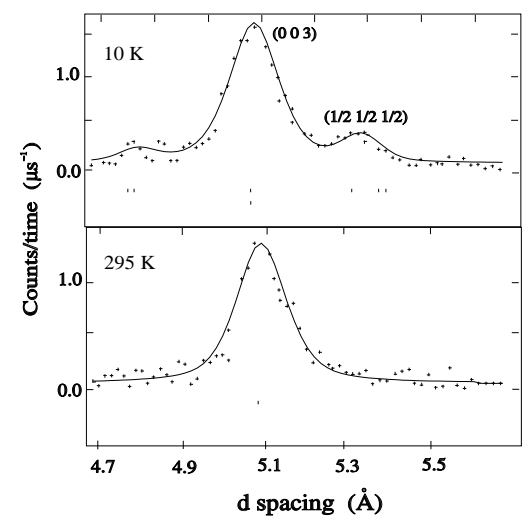

Fig. 12. Part of the neutron diffraction pattern of $\mathrm{Pb}_{2} \mathrm{Sr}_{2} \mathrm{Cu}_{2} \mathrm{RuO}_{8} \mathrm{Cl}$ showing the weak nuclear [003] peak along with the $\left[\frac{1}{2} \frac{1}{2} \frac{1}{2}\right]$ antiferromagnetic Bragg peak at $10 \mathrm{~K}$. The same portion at $290 \mathrm{~K}$ is shown below for reference.

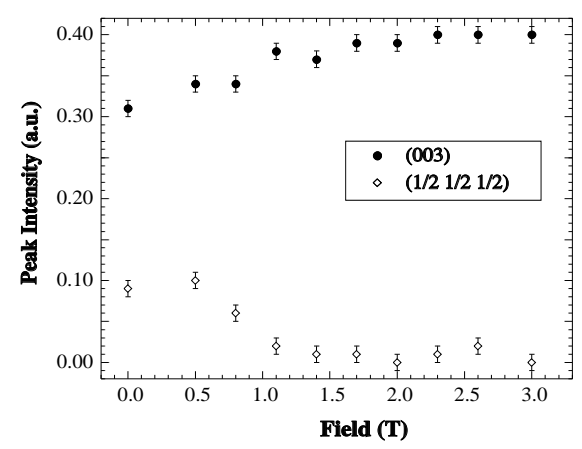

Fig. 13. Field dependence of the intensity of the magnetic $\left[\frac{1}{2} \frac{1}{2} \frac{1}{2}\right]$ and nuclear [003] neutron diffraction peaks.

A ferromagnetic transition at $\mathrm{T}_{\mathrm{M}}=117(1) \mathrm{K}$ was evidenced from SQUID magnetometry measurements on $\mathrm{Pb}_{2} \mathrm{Sr}_{2} \mathrm{Cu}_{2} \mathrm{RuO}_{8} \mathrm{Cl}$ (Fig. 14) despite the observation of antiferromagnetism in the variable temperature neutron diffraction study. Similar SQUID magnetometry results were observed for $\mathrm{RuSr}_{2} \mathrm{GdCu}_{2} \mathrm{O}_{8}$ [1]. No separate ferromagnetic transition was observed for the " $\mathrm{SrRuO}_{3}$ " secondary phase showing that substitutions by $\mathrm{Pb}$ or $\mathrm{Cu}$ have suppressed the 


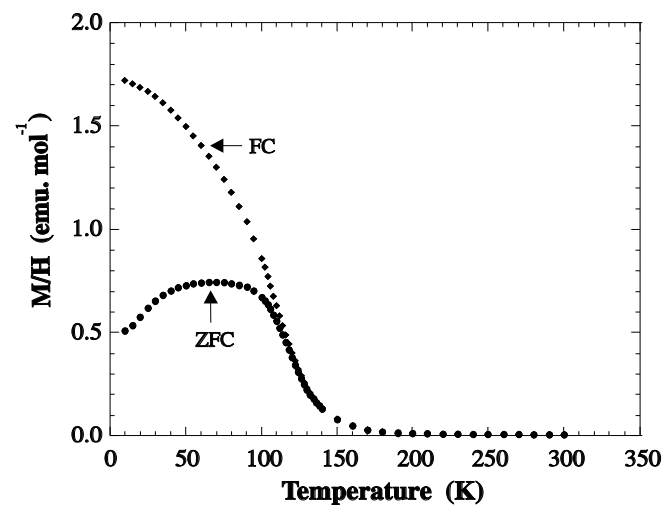

Fig. 14. Variable temperature molar susceptibility for $\mathrm{Pb}_{2} \mathrm{Sr}_{2} \mathrm{Cu}_{2} \mathrm{RuO}_{8} \mathrm{Cl}$.

ferromagnetism found in pure $\mathrm{SrRuO}_{3}\left(\mathrm{~T}_{\mathrm{M}}=165 \mathrm{~K}\right)$; a suppression of the ferromagnetic state in the $\mathrm{SrRu}_{1-x} \mathrm{~Pb}_{x} \mathrm{O}_{3}$ system [42] has been reported previously. Furthermore there was no observable ferromagnetic contribution from the " $\mathrm{SrRuO}_{3}$ " phase in the $10 \mathrm{~K}$ neutron pattern. Magnetic hysteresis loops recorded at $10 \mathrm{~K}$ (Fig. 15) yielded a moment of $0.8(1) \mu_{\mathrm{B}}$ per $\mathrm{Ru}$ atom. The presence of $19 \% \mathrm{SrRuO}_{3}$ which has a $\mu_{\mathrm{Ru}}=1.4 \mu_{\mathrm{B}}$ at $5 \mathrm{~T}$ [42] could only contribute $\sim 0.3$ $\mu_{\mathrm{B}}$ to the sample magnetisation per $\mathrm{Ru}$, even if it were stoichiometric. Hence it was concluded that the saturated $\mathrm{Ru}$ moment in $\mathrm{Pb}_{2} \mathrm{Sr}_{2} \mathrm{Cu}_{2} \mathrm{RuO}_{8} \mathrm{Cl}$ is $0.5-$ $0.8 \mu_{\mathrm{B}}$ which is comparable to the value of $1.09 \mu_{\mathrm{B}}$ in $\mathrm{RuSr}_{2} \mathrm{GdCu}_{2} \mathrm{O}_{8}[31,32]$. A narrowing of the hysteresis loop for $\mathrm{Pb}_{2} \mathrm{Sr}_{2} \mathrm{Cu}_{2} \mathrm{RuO}_{8} \mathrm{Cl}$ was observed at low fields, indicative of a spin flop transition from weak ferromagnetism to full ferromagnetism above $0.5 \mathrm{~T}$ consistent with the variable field neutron diffraction results. It was therefore concluded that $\mathrm{Pb}_{2} \mathrm{Sr}_{2} \mathrm{Cu}_{2} \mathrm{RuO} \mathrm{O}_{8} \mathrm{Cl}$ is a canted antifer-

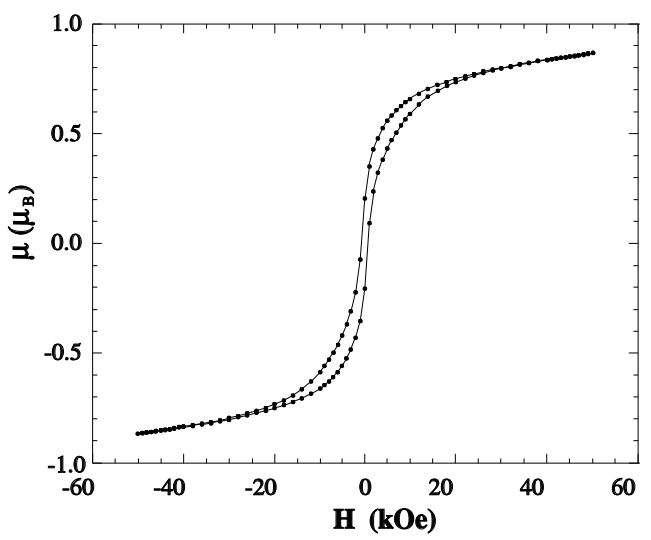

Fig. 15. Variable field magnetisation data for the $\mathrm{Pb}_{2} \mathrm{Sr}_{2} \mathrm{Cu}_{2} \mathrm{RuO}_{8} \mathrm{Cl}$ sample. 
romagnet with an ordered moment of $1.1 \mu_{\mathrm{B}}$ per $\mathrm{Ru}$ in zero field below $\mathrm{T}_{\mathrm{M}}=$ $117 \mathrm{~K}$. The $\mathrm{Ru}$ spins cant into a fully ferromagnetic arrangement above $\mathrm{H}=0.5$ $\mathrm{T}$ giving a saturated $\mathrm{Ru}$ moment of $0.5-0.8 \mu_{\mathrm{B}}$.

\section{Conclusions}

The structures of the (ferro)magnetic superconductor $\mathrm{RuSr}_{2} \mathrm{GdCu}_{2} \mathrm{O}_{8}$ and the new layered ruthenocuprate $\mathrm{Pb}_{2} \mathrm{Sr}_{2} \mathrm{Cu}_{2} \mathrm{RuO}_{8} \mathrm{Cl}$ have been studied. There are marked similarities in both the structure and basic magnetic properties of these materials. Both materials contain $\mathrm{CuO}_{5}$ units separated by $\mathrm{RuO}_{2}$ planes (Figs. 1 and 10). The $\mathrm{RuO}_{6}$ octahedra are rotated by approximately $13^{\circ}$ in both materials due to a bond mismatch between the in-plane $\mathrm{Ru}-\mathrm{O}$ and $\mathrm{Cu}-\mathrm{O}$ bond lengths. Tilts of the $\mathrm{RuO}_{6}$ octahedra which reduce the $\mathrm{Cu}-\mathrm{O}-\mathrm{Cu}$ angle to $\sim 173^{\circ}$ are also observed for both $\mathrm{RuSr}_{2} \mathrm{GdCu}_{2} \mathrm{O}_{8}$ and $\mathrm{Pb}_{2} \mathrm{Sr}_{2} \mathrm{Cu}_{2} \mathrm{RuO}_{8} \mathrm{Cl}$. $\mathrm{RuSr}_{2} \mathrm{GdCu}_{2} \mathrm{O}_{8}$ and $\mathrm{Pb}_{2} \mathrm{Sr}_{2} \mathrm{Cu}_{2} \mathrm{RuO}_{8} \mathrm{Cl}$ are believed to be canted antiferromagnets in zero field below $\mathrm{T}_{\mathrm{M}}=132 \mathrm{~K}$ and $117 \mathrm{~K}$ respectively. The canting of the $\mathrm{Ru}$ moments arises due to a Dzyaloshinsky-Moriya interaction between neighbouring $\mathrm{Ru}$ moments which is non-zero due to the tilts and rotations of the $\mathrm{RuO}_{6}$ octahedra. Upon the application of magnetic field the $\mathrm{Ru}$ moments cant into a ferromagnetic arrangement above $\mathrm{H}=0.5 \mathrm{~T}$ giving a saturated $\mathrm{Ru}$ moment of $0.5-0.8$ $\mu_{\mathrm{B}}$ and $1.09 \mu_{\mathrm{B}}$ in $\mathrm{Pb}_{2} \mathrm{Sr}_{2} \mathrm{Cu}_{2} \mathrm{RuO}_{8} \mathrm{Cl}$ and $\mathrm{RuSr}_{2} \mathrm{GdCu}_{2} \mathrm{O}_{8}$ respectively. The maximum $\mathrm{T}_{\mathrm{M}}$ is plotted against the $\mathrm{Ru}-\mathrm{Ru}$ interplanar distance for the three ruthenocuprate structure types $\mathrm{RuSr}_{2} \mathrm{GdCu}_{2} \mathrm{O}_{8}, \mathrm{RuSr}_{2} \mathrm{Eu}_{1.4} \mathrm{Ce}_{0.6} \mathrm{Cu}_{2} \mathrm{O}_{10}$ [43] and $\mathrm{Pb}_{2} \mathrm{Sr}_{2} \mathrm{Cu}_{2} \mathrm{RuO}_{8} \mathrm{Cl}$ in Fig. 16. The inverse correlation shows that $\mathrm{T}_{\mathrm{M}}$ is limited by the interplanar superexchange coupling between $\mathrm{RuO}_{2}$ planes, as expected for these layered magnetic systems.

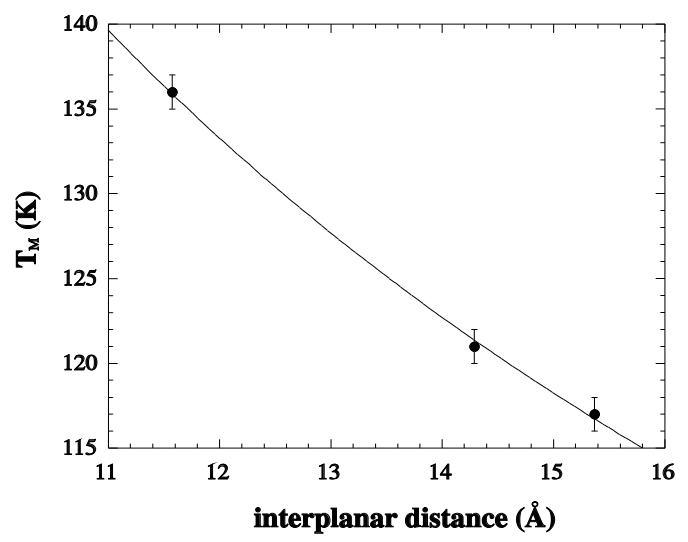

Fig. 16. The variation of $\mathrm{T}_{M}$ with $\mathrm{Ru}-\mathrm{Ru}$ interplanar distance in ruthenocuprates.

Doping studies of $\mathrm{RuSr}_{2} \mathrm{GdCu}_{2} \mathrm{O}_{8}$ have shown that the overlap of the $\mathrm{Cu}$ $3 \mathrm{~d}_{x^{2}-y^{2}}$ and the $\mathrm{Ru} \mathrm{t}_{2 g}$ bands leads to the hole doping of the $\mathrm{CuO}_{2}$ planes re- 
quired for superconductivity. A tuning of both the ferromagnetic and superconducting transitions is observed with increasing $x$ in the $\mathrm{Ru}_{1-x} \mathrm{M}_{x} \mathrm{Sr}_{2} \mathrm{GdCu}_{2} \mathrm{O}_{8}$ solid solutions $(\mathrm{M}=\mathrm{Nb}, \mathrm{Sn})$. Despite the structural and magnetic similarities of $\mathrm{RuSr}_{2} \mathrm{GdCu}_{2} \mathrm{O}_{8}$ and $\mathrm{Pb}_{2} \mathrm{Sr}_{2} \mathrm{Cu}_{2} \mathrm{RuO}_{8} \mathrm{Cl}$, the carrier distribution in $\mathrm{Pb}_{2} \mathrm{Sr}_{2} \mathrm{Cu}_{2}-$ $\mathrm{RuO}_{8} \mathrm{Cl}$ appears to be different. $\mathrm{RuSr}_{2} \mathrm{GdCu}_{2} \mathrm{O}_{8}$ is superconducting below $\mathrm{T}_{\mathrm{c}}$ $=37 \mathrm{~K}$ whereas $\mathrm{Pb}_{2} \mathrm{Sr}_{2} \mathrm{Cu}_{2} \mathrm{RuO}_{8} \mathrm{Cl}$ is semiconducting and the longer apical $\mathrm{Cu}$ $\mathrm{O}$ distance suggests that the $\mathrm{CuO}_{2}$ planes are essentially undoped. The $\mathrm{RuO}_{2}$ planes of $\mathrm{Pb}_{2} \mathrm{Sr}_{2} \mathrm{Cu}_{2} \mathrm{RuO}_{8} \mathrm{Cl}$ thus contain $\mathrm{Ru}^{5+}$ with little or no electron doping to the $\mathrm{Ru}^{4+}$ state. This confirms that the weak ferromagnetism in the layered ruthenocuprates arises from the local symmetry breaking distortions rather than a mixed $\mathrm{Ru}^{4+} / \mathrm{Ru}^{5+}$ state.

\section{Acknowledgements}

We thank EPSRC for the provision of research grant GR/M59976, synchrotron and neutron beam time, and a studentship for ACM. We thank I. Pape and A. N. Fitch (ESRF), P. Radaelli (RAL), Jeff Tallon and colleagues (DSIR, New Zealand) and our coworkers W. Zhou, J. A. McAllister, V. Janowitz and L. D. Stout.

\section{References}

1. J. L. Tallon, C. Bernhard, M. Bowden, P. Gilberd, T. Stoto and D. Pringle: IEEE. Trans. Appl. Supercon. 9, 1696 (1999)

2. L. Bauernfeind, W. Widder and H. F. Braun: Physica C 254, 151 (1995)

3. L. Bauernfiend, W. Widder and H. F. Braun: J. Low Temp. Phys. 105, 1605 (1996)

4. C. Bernhard, J. L. Tallon, C. Niedermayer, T. Blasius, A. Golnik, E. Brucher, R. K. Kremer, D. R. Noakes, C. E. Stronach and E. J. Ansaldo: Phys. Rev. B 59, 14099 (1999)

5. A. C. Mclaughlin, W. Zhou, J. P. Attfield, A. N. Fitch and J. L. Tallon: Phys. Rev. B 60, $7512(1999)$

6. A. C. Mclaughlin, J. P. Attfield and J. L. Tallon: Int. J. Inorg. Mater. 2, 95 (2000)

7. K. B. Tang, Y. T. Qian, L. Yang, Y. D. Zhao and Y. H. Zhang: Physica C 282-287, $947(1997)$

8. I. Felner, U. Asaf, S. Reich and Y. Tsabba: Physica C 163, 311 (1999)

9. J. L. Tallon, J. W. Loram, G. V. M. Williams and C. Bernhard: Phys. Rev. B 61, 6471 (2000)

10. J. W. Lynn, B. Keimer, C. Ulrich, C. Bernhard and J. L. Tallon: Phys. Rev. B 61, $14964(2000)$

11. O. Chmaissam, J. D. Jorgensen, H. Shaked, P. Dollar and J. L. Tallon: Phys. Rev. B 61, $6401(2000)$

12. X. H. Chen, Z. Sun, K. Q. Wang, S. Y. Li, Y. M. Xiong, M. Yu and L. Z. Cao: Phys. Rev. B 63, 54506 (2001)

13. K. Nakamura, K. T. Park, A. J. Freeman and J. D. Jorgensen: Phys. Rev. B 63, 24507 (2001)

14. Y. Furukawa, S. Takada, A. Yamanaka and K. Kumagai: Physica C 341, 453 (2000) 
15. C. Bernhard, J. L. Tallon, E. Brucher and R. K. Kremer: Phys. Rev. B 61, 14960 (2000)

16. A. Fainstein, P. Etchegoin, H. J. Trodahl and J. L. Tallon: Phys. Rev. B 61, 15468 (2000)

17. A. Butera, A. Fainstein, E. Winkler and J. L. Tallon: Phys. Rev. B 63, 54442 (2001)

18. A. Fainstein, E. Winkler, A. Butera and J. L. Tallon: Phys. Rev. B 60, 12597 (1999)

19. J. D. Jorgensen, O. Chmaissem, H. Shaked, S. Short, P. W. Klamut, B. Dabrowski, and J. L. Tallon: Phys. Rev. B 63, 54440 (2001)

20. R. S. Liu, L. Y. Jang, H. H. Hung and J. L. Tallon: Phys. Rev. B 63, 212507 (2001)

21. A. V. Boris, P. Mandal, C. Bernhard, N. N. Kovaleva, K. Pucher, J. Hemberger and A. Loidl: Phys. Rev. B 63, 184505 (2001)

22. H. Takagiwa, J. Akimitsu, H. Kawano-Furukawa and H. Yoshizawa: J. Phys. Soc. Jpn. 70, $333(2001)$

23. C. S. Knee, B. D. Rainford and M. T. Weller: J. Mater. Chem. 10, 2445 (2000)

24. A. C. Mclaughlin, J. A. McAllister, L. D. Stout and J. P. Attfield: Solid State Sciences, in press (2002)

25. R. J. Cava, A. W. Hewat, E. A. Hewat, B. A. Batlogg, M. Marezio, K. M. Rabe, J. J. Krajewski, W. F. Peck Jr. and L. W. Rupp Jr: Physica C 165, 419 (1990)

26. J. E. McCrone, J. R. Cooper and J. L. Tallon: J. Low Temp. Phys. 117, 1199 (1999)

27. I. Dzyaloshinksy: Sov. Phys. JETP 5, 1259 (1957)

28. T. Moriya: Phys. Rev. 120, 91 (1960)

29. I. D. Brown: J. Solid State Chem. 82, 122 (1989)

30. I. D. Brown: J. Solid State Chem. 90, 155 (1991)

31. A. C. Mclaughlin, V. Janowitz, J. A. McAllister and J. P. Attfield: Chem. Commun. $1331(2000)$

32. A. C. Mclaughlin, V. Janowitz, J. A. McAllister and J. P. Attfield: J. Mater. Chem. 11, $173(2001)$

33. M. R. Presland, J. L. Tallon, R. G. Buckley, R. S. Liu and N. E. Flower: Physica C 176, 95 (1991)

34. P. W. Klamut, B. Dabrowski, S. Kolesnik, M. Maxwell and J. Mais: Phys. Rev. B 63, $224512(2001)$

35. R. S. Liu, P. P. Edwards, Y. T. Huang, S. F. Wu and P. T. Wu: J. Solid State Chem. 86, $334(1990)$

36. R. C. Rouse: Am. Miner. 56, 652 (1971)

37. J. Pannetier and P. J. Batail: J. Solid State Chem. 39, 15 (1981)

38. R. K. Li: Physica C 277, 252 (1997)

39. R. Li: J. Solid State Chem. 130, 154 (1997)

40. R. J. Crooks, C. S. Knee and M. T. Weller: Chem. Mater. 10, 4169 (1998)

41. A. C. Mclaughlin, J. A. McAllister, L. D. Stout and J. P. Attfield: (submitted).

42. G. Cao, S. McCall, J. Bolivar, M. Shepard, F. Freibert, P. Henning and J. E. Crow: Phys. Rev. B 54, 15144 (1996)

43. I. Felner, U. Asaf, Y. Levi and O. Millo: Phys. Rev. B 55, 3374 (1997) 